\title{
How tall is an elephant? Two methods for estimating elephant height
}

\author{
Francesca Della Rocca
}

Della Rocca, F. 2007. How tall is an elephant? Two methods for estimating elephant height. - Web Ecol. 7: 1-10.

\begin{abstract}
Shoulder height is a reliable indicator of age for African elephants (Loxodonta africana), and is therefore an important parameter to be recorded in field studies of population ecology of these pachyderms. However, it can be somewhat difficult to estimate with precision the shoulder height of free-ranging elephants because of several reasons, including the presence of drops and vegetation cover and the potential dangerousness of approaching them in the wild. Here I test two alternative models for estimating shoulder height of elephants. In both models, the equipment needed to generate the height estimates is minimal, and include a telemeter and a digital photo-camera furnished with an $x 16$ zoom. The models are based respectively on a linear regression approach and on a geometric formula approach, and put into a relationship the linear distance between the observer and the animal, the number of pixels of an elephant silhouette as taken from digital photos, and the absolute height of the animal. Both methods proved to have a very small measurement error, and were thus reliable for field estimates of elephant shoulder heights. The model based on a geometric formula was used to estimate the shoulder height distribution of an elephant population in a savannah region of West Africa (Zakouma National Park, Chad). I demonstrated that Zakouma elephants were among the tallest populations in Africa, with growth rates being highest throughout the first five years of life.
\end{abstract}

F. Della Rocca (drfrancesca@tiscalinet.it),Dipt. di Biologia Animale e dell'Uomo, Univ. di Roma 'La Sapienza', viale dell'Università 32, 00100-Roma, Italy.

Shoulder height is considered a reliable indicator of age for African elephants that grow throughout their lifetime (Lindeque and van Jaarsveld 1993, Shrader et al. 2006b). Many techniques have been used to estimate elephant age, including back length (Laws 1969, Croze 1972), posterior foot print (Western 1983), progressive molar growth (Laws 1966), as well as characteristics identifiable through direct observation (Moss 1996). Among these latter, body size, appearance of jaws (at ca two-three yr old) and their growth, markings that arise with older age (ears turning outwards, snout elongation, etc.), and shoulder height (Laws 1966, Douglas-Hamilton 1972, Laws et al. 1975,
Jachmann 1988, Lee and Moss 1995) have been frequently used in population studies of these mammals.Currently, the majority of studies on elephants still depend on the assessment of body size to reconstruct the age structure of wild populations (Wittemyer 2001, Morgan and Lee 2003).

My aims in this paper are (i) to compare two alternative and simple models (one based on the employment of a linear regression method, and the other based on digital photo-grammetry and laser rangefinder (Shrader et al. 2006a) to evaluate their performance with estimates of elephant heights in the field, and (ii) to validate these models 
by using a field study of a population of African elephants (Loxodonta africana) from Zakouma National Park, Chad (West Africa). These techniques are especially valuable because require only a few simple instruments (for instance, a digital camera to take elephant pictures and an optical range-finder to measure the distance from the elephant to the camera), and are therefore very useful in logistically difficult contexts as those that ecologists usually experience in most African countries.

\section{Material and methods}

\section{Model I: a linear regression approach}

The application of this method requires the employment of two instruments: (i) a telemeter for evaluating the linear distance between the observer and the target animal, and (ii) a digital camera furnished with an x16 zoom. The model allows directly relate two variables: the linear distance between the observer and the target animal and the number of pixels relative to the silhouette of the photographed animal. By knowing these two variables, it is possible to accurately estimate the body size of the target elephant.

\section{Structure and calibration}

Five cardboard elephant silhouettes of known height (50, $100,150,200$, and $250 \mathrm{~cm}$ ), and with a grey coloration similar to the natural coloration of African elephants, were photographed with a digital camera from different distances, increasing by two-by-two $\mathrm{m}$ steps each time. At each distance step, the elephant silhouette was also shot by a Canon MVX 150i television camera, with a fixed $\times 16$ zoom.

The shooting procedure was done at a site inside urban Rome (Circo Massimo). This site was selected as a trial site because it was the only area in Rome with open grassy structure and regular distributed tree coverage at the borders, i.e. the conditions that naturally occur in an African savannah. The trials were conducted at midday, with a sunny weather and terse sky.
A 100-m wire was placed along a straight line and fixed at the extremities through two pickets. At one of the extremities, the observed was positioned together with his photographic equipment. Along the wire, starting at a distance of $40 \mathrm{~m}$ from the observer, all the spots situated at successive distance intervals of two $\mathrm{m}$ were registered. The elephant silhouettes of all sizes were shot every two $\mathrm{m}$ starting at a distance of $40 \mathrm{~m}$ from the observer, and were also photographed at every distance interval. Thus, a total of 31 digital photos were done for each silhouette. At each distance interval, the linear distance between the observer and the silhouette was also measured by the telemeter. The minimum distance of $40 \mathrm{~m}$ from the observer was selected because it is the minimum distance from which a whole silhouette of $50 \mathrm{~cm}$ height was wholly visible inside the photo-camera, and therefore included into a single digital photo.

A database was created for each silhouette, including (i) the real distance, (ii) the distance measured by the telemeter, (iii) the digital photo, and (iv) the time code of the photo into the tape. Each photo was cut out using Adobe Photoshop, and its corresponding number of pixels was calculated. In order to estimate a measure of variability in this count, this operation was repeated ten times, and a table was built for each photo with ten independent counts of the number of pixels of each silhouette.

A regression model was then built, with $\mathrm{X}$ being the distance and $\mathrm{Y}$ the number of pixels.

\section{Model II: a geometric approach}

\section{Structure and calibration}

My geometric approach is similar to that described by Shrader et al. (2006a). A formula related to the digital image of an elephant was used to estimate the height of an individual in cm (Fleury and Mathieu 1956). The formula uses three variables: (i) the distance from the elephant to the camera, (ii) the size of elephant image in pixels, and (iii) the focal length of the digital video-camera (Fig. 1).

The model was calibrated using a cardboard elephant silhouette of known height placed at different distances

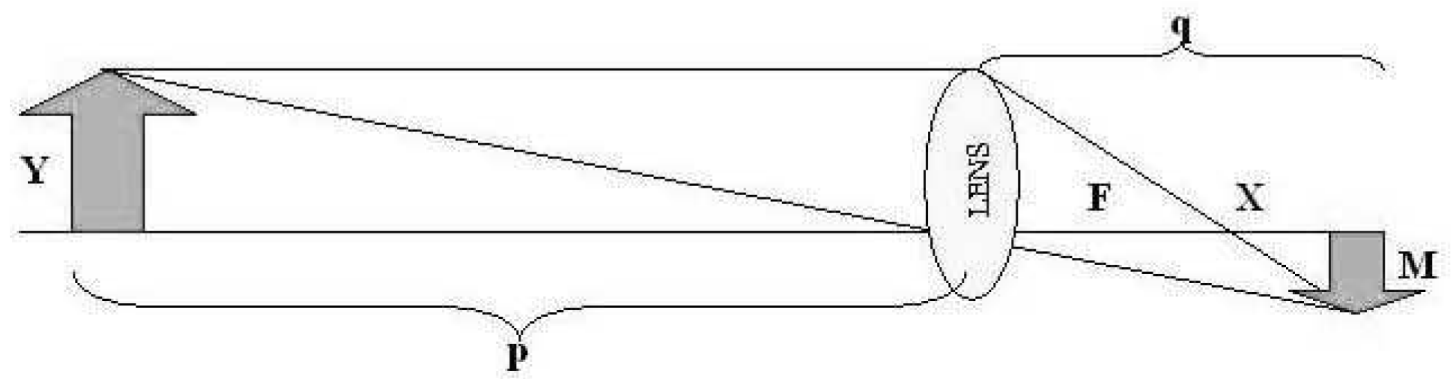

Fig 1. Geometrical formula related to an elephant digital image. $Y=(D / F) M$, where $Y$ is the height of the elephant at the shoulder, $D$ is the distance from the elephant (p) to the camera, $\mathrm{F}$ is the focal length $(200 \mathrm{~mm})$, and $\mathrm{M}$ is the size of elephant image. $\mathrm{Y} / \mathrm{M}=\mathrm{p} / \mathrm{q}$, where $\mathrm{q}=\mathrm{F}+\mathrm{X}$. In this case $\mathrm{X}$ is irrelevant, so $\mathrm{q}=\mathrm{F}$ and $\mathrm{Y}=\mathrm{Mp} / \mathrm{F}$, where $\mathrm{p}=\mathrm{D}$. 
(these silhouettes are of the same size than those used for Model I calibration). To correct for the rangefinder's error, each distance was measured both by the rangefinder and by a measuring tape (in $\mathrm{cm}$ ). A picture of the cardboard silhouette was taken at each distance starting at $40 \mathrm{~m}$ up to $100 \mathrm{~m}$ (31 distance classes of two $\mathrm{m}$ each).

\section{Estimating the height of the elephants in Zakouma National} Park, Chad

Model II was used for estimating the height distribution of African elephants in the Zakouma National Park, Chad. The park (ca $305000 \mathrm{ha}$ ) is located in S-E Chad and is included in the Salamat and Guéra prefectures, between $10^{\circ} 34^{\prime}$ and $11^{\circ} 03^{\prime} \mathrm{N}$ and $19^{\circ} 21^{\prime}$ and $20^{\circ} 00^{\prime} \mathrm{E}$ (Fig. 2).

The study area is fairly flat and reaches its highest point (415 m asl) near the village of Zakouma. The Eastern part of the Park is crossed by rivers running from $\mathrm{N}$ to $\mathrm{S}$, among which the Bahrs Korom, Biheda, Djourf, Rossé, Sagma, and Salamat rivers are the most important. The climate is typically Soudano-Sahelian (Aubréville 1950) with seasonal rainfall from March to November estimated in $853 \mathrm{~mm} \mathrm{yr}^{-1}$ at Zakouma station for the 1996-1998 period (Dejace 2002). The vegetation varies according to the rainfall gradient: Acacia seyal Del. savanna is dominant in the north, but is replaced by Combretaceae savannah (Combretum glutinosum Perr.) in the central part. The southern part of the park is mostly Caesalpiniaceae savannah (Afzelia africana Smith) (Calenge et al. 2002).

Unlike many other parks across Western and Central Africa, the Zakouma National Park still offers strong and healthy populations of many mammals such as elephants, buffaloes (Syncerus caffer), giraffes (Giraffa camelopardalis), roans (Hyppotragus equines), greater kudu (Tragelaphus strepsiceros) and lions (Panthera leo), as well as of many other animals such as reptiles and birds (Dejace et al. 2000).

The elephant population was estimated to be $4351 \pm$ 1354 individuals, being the Chad's largest. A recent study of movement patterns suggested that this population spends the main part of the dry season inside the Zakouma National Park. Elephants are primarily concentrated in the Eastern part of the park during the dry season, and move into the neighbouring areas soon after the arrival of the first rains (Maillard et al. 2001; Dolmia and Cornelis 2004). However, the ecology of the Zakouma elephants is still poorly known, and is currently under study by the author for the fulfilment of her Ph.D.
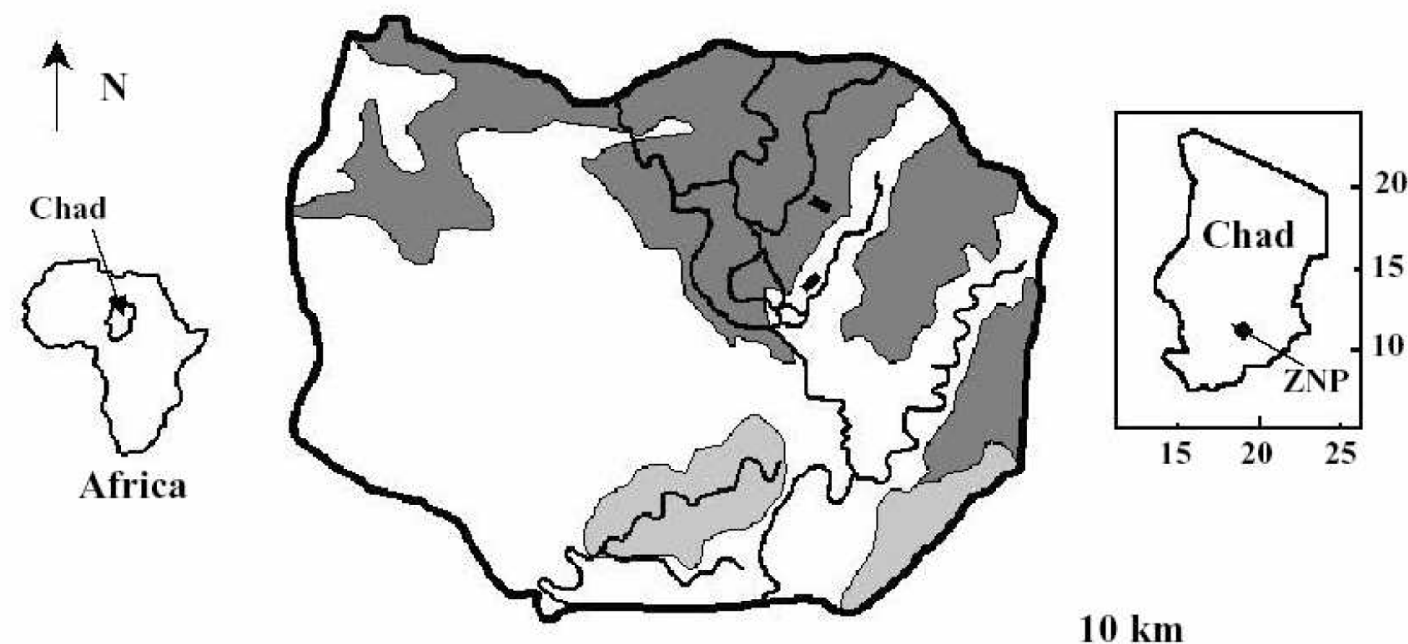

\section{$10 \mathrm{~km}$}

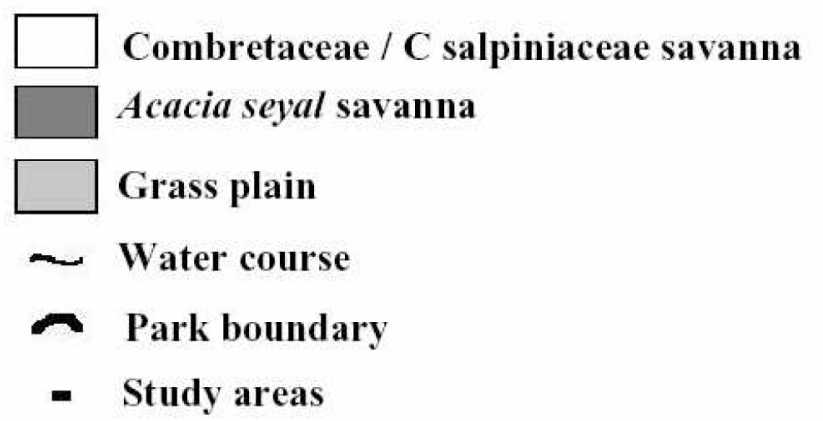

Fig 2. Map of Zakouma National Park, Chad (redrawn from Calenge et al. 2002). 
Between January and April 2004, 1228 free-ranging elephants were observed and videotaped. Next, 767 individuals were identified from digital images. Sex was determined for adult individuals by head shapes and genitalia (Moss 1996). For many newborn and young individuals it was impossible to determine their sex due to vegetation cover; these individuals were grouped into the "undetermined" category.

Each elephant was photographed in the field using a digital video-camera (Canon MVX150i) with a fixed focus distance. The distance from the video-camera to the elephants was recorded using an optical range-finder (Bushnell Yardage Pro Legend). The distance from the elephant ranged between $40-70 \mathrm{~m}$ depending on visibility conditions and elephant approachability.

From the digital images, each elephant shoulder height was measured in pixels as the height from the top of the shoulder blade to the ground (Fig. 3). To calculate shoulder height, I included in the analysis only those photographs with elephants on completely open ground, i.e. where the vegetation cover did not hinder the accurateness of my estimates. Individual reconnaissance was based on the identification of unique features characterizing each animal, for instance the size and shape of tusks and the characteristic patterns of the ears (Douglas Hamilton 1972), and further confirmed by the use of an appropriate software (Petriccione et al. 2006).

Age was estimated from shoulder height by applying a recent model of growth curve (Shrader et al. 2006b) derived from the general Von Bertalanffy growth curve: $h_{i}=$ $h_{b}+\left(H_{\infty}-h_{b}\right)\left(1-e^{k t}\right)$, where $h_{i}$ is the shoulder height, $h_{b}$ is the shoulder height at birth, $\mathrm{H}_{\infty}$ is the asymptotic shoulder height, $\mathrm{k}$ is a constant determining the rate of growth and $t$ is the age of an individual (Hanks 1972). The functions, relative to males and females, were: $h i=104.7+(312.0-$ $104.7)\left(1-e^{-0.069 x}\right)$ for males, and $h i=97.6+(231.6-$ 97.6) $\left(1-e^{-0.146 x}\right)$ for females.

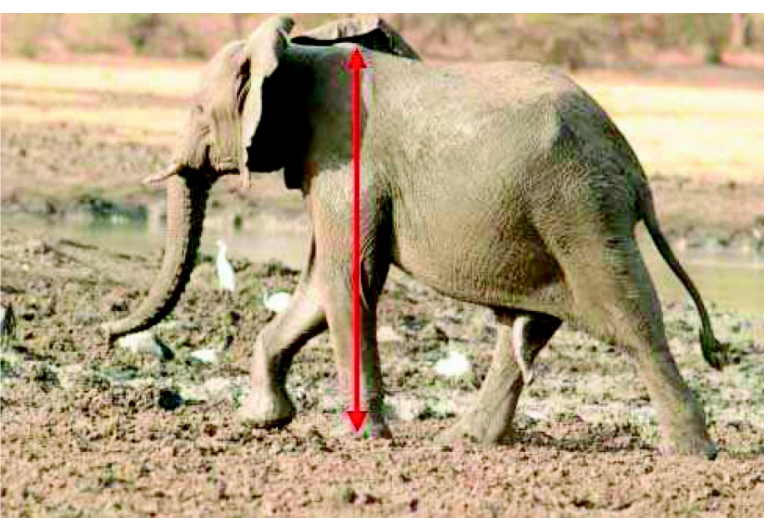

Fig. 3. The arrow indicates the shoulder height of a male elephant in the Zakouma National Park, Chad.
These functions allowed for the extrapolation of age up to an age of $14 \mathrm{yr}$ for females and up to an age of $25 \mathrm{yr}$ for males. After these ages, it is inaccurate to use the Von Bertalanffy growth curve, and hence I used the visual assessment method prescribed by Moss (1996). It consists in identifying the morphological peculiarities of each individual. Indeed, in older males head gets larger across the forehead and at the base of the tusks, giving the head a more hour-glass appearance from a front view as he gets older. Other characteristics used by Moss' method are the size of the head in relation to the body and the thickness of the neck and trunk. In older females tusk circumference and length increase as females get older. Overall appearance is also an aid. Older females get bonier around the shoulders and head, and the tops of their ears fold down more and appear to be positioned lower in relation to the head and shoulders than those of younger females. Indeed, the standard deviations of the ages estimated for elephants from their shoulder heights increased with increasing shoulder height in this study. Standard deviations increased markedly and attained values higher than five at shoulder heights $>215 \mathrm{~cm}$ for females (Fmax test for equality of variances $F_{2,99}=16.83, p<0.01$ ). For males, the standard deviations changed at a more gradual rate, and exceeded a value of 5 at shoulder height higher than 290 $\mathrm{cm}$.

All individuals were classified into eight age categories: 0-1 yr (newborn), 2-5 yr (young1), 6-10 yr (young2), 11-15 yr (subadult1), 16-20 yr (subadult2), 21-35 yr (adult1), 36-50 yr (adult2), and > 50 yr (adult3).

Statistical analyses were done with SPSS (version 11.0) software, all tests being two-tailed and alpha set at 5\%. I employed parametric tests when the data distribution satisfied the criteria of normality and homoscedasticity.

\section{Results and discussion}

\section{Model I}

The mean number of pixels was significantly different among the various distances (one-way ANOVA: $\mathrm{F}_{30,279}=$ 28318.63, $\mathrm{p}<0.0001$ ), meaning that despite the small size of the distance intervals (two $\mathrm{m}$ ), it was sufficient to get a number of pixels significantly different at the various distance classes.

Potential errors in the measurements are linked to two independent sources: the human error in measuring the pixel size on the digital images (i.e., during the cutting out operation of the silhouette from the surroundings of the photo), and the error due to the fact that each photo tends to be less well-defined at longer distances, thus introducing some noise in the pixel exact counts. However, this latter source of error is already taken into consideration in the regression line. On the other hand, the human error was 
Table 1. Mean and dispersion measures for the human error in the measurement of the number of pixels included in a cardboard elephant silhouette at the various distance intervals considered in this study. Symbols: D $40=$ distance of $40 \mathrm{~m}$, etc.

\begin{tabular}{|c|c|c|c|c|c|c|c|c|}
\hline Distance & $\mathrm{n}$ & Mean & $\begin{array}{c}-95 \% \\
\text { conf. int. }\end{array}$ & $\begin{array}{c}+95 \% \\
\text { conf. Ind. }\end{array}$ & Min & Max & SD & SE \\
\hline D40 & 10 & 177.0 & 176.6 & 177.3 & 176 & 178 & 0.4 & 0.1 \\
\hline D42 & 10 & 169.1 & 168.3 & 169.8 & 167 & 170 & 0.9 & 0.3 \\
\hline D44 & 10 & 160.8 & 160.4 & 161.1 & 160 & 161 & 0.4 & 0.1 \\
\hline D46 & 10 & 154.9 & 154.1 & 155.6 & 153 & 156 & 0.9 & 0.3 \\
\hline D50 & 10 & 141.6 & 141.2 & 141.9 & 141 & 142 & 0.5 & 0.1 \\
\hline D52 & 10 & 138.6 & 138.0 & 139.1 & 138 & 140 & 0.6 & 0.2 \\
\hline D54 & 10 & 131.9 & 131.4 & 132.3 & 131 & 133 & 0.5 & 0.1 \\
\hline D56 & 10 & 128.3 & 127.8 & 128.7 & 128 & 130 & 0.6 & 0.2 \\
\hline D58 & 10 & 124.2 & 123.8 & 124.5 & 124 & 125 & 0.4 & 0.1 \\
\hline D60 & 10 & 120.4 & 120.0 & 120.7 & 120 & 121 & 0.5 & 0.1 \\
\hline D62 & 10 & 117.7 & 117.3 & 118.0 & 117 & 118 & 0.4 & 0.1 \\
\hline D64 & 10 & 113.5 & 112.9 & 114.0 & 112 & 114 & 0.7 & 0.2 \\
\hline D66 & 10 & 108.7 & 108.3 & 109.0 & 108 & 109 & 0.4 & 0.1 \\
\hline D68 & 10 & 106.0 & 105.6 & 106.3 & 105 & 107 & 0.4 & 0.1 \\
\hline D70 & 10 & 105.1 & 104.6 & 105.5 & 104 & 106 & 0.5 & 0.1 \\
\hline D72 & 10 & 102.2 & 101.7 & 102.6 & 101 & 103 & 0.6 & 0.2 \\
\hline D74 & 10 & 99.2 & 98.7 & 99.6 & 98 & 100 & 0.6 & 0.2 \\
\hline D76 & 10 & 99.5 & 99.1 & 99.8 & 99 & 100 & 0.5 & 0.1 \\
\hline D80 & 10 & 91.2 & 90.6 & 91.7 & 90 & 92 & 0.7 & 0.2 \\
\hline D82 & 10 & 90.5 & 89.9 & 91.0 & 89 & 91 & 0.7 & 0.2 \\
\hline D84 & 10 & 86.9 & 86.4 & 87.3 & 86 & 88 & 0.5 & 0.1 \\
\hline D86 & 10 & 81.2 & 80.7 & 81.6 & 80 & 82 & 0.6 & 0.2 \\
\hline D88 & 10 & 80.3 & 79.9 & 80.6 & 80 & 81 & 0.4 & 0.1 \\
\hline D90 & 10 & 79.8 & 79.4 & 80.1 & 79 & 80 & 0.4 & 0.1 \\
\hline D92 & 10 & 79.9 & 79.6 & 80.1 & 79 & 80 & 0.3 & 0.1 \\
\hline D94 & 10 & 76.8 & 76.3 & 77.2 & 76 & 78 & 0.6 & 0.2 \\
\hline D96 & 10 & 75.1 & 74.8 & 75.3 & 75 & 76 & 0.3 & 0.1 \\
\hline D98 & 10 & 73.2 & 72.8 & 73.5 & 73 & 74 & 0.4 & 0.1 \\
\hline D100 & 10 & 71.0 & 70.6 & 71.3 & 70 & 72 & 0.4 & 0.1 \\
\hline
\end{tabular}

estimated by doing ten independent replicates of the same measurement for each distance interval. The means and dispersion measures for each of these distance classes are reported in Table 1 . The mean error in the number of pixels was 0.1687 (range $0-0.3145, \mathrm{n}=31, \mathrm{SD}=0.068, \mathrm{SE}=$ 0.0122 ), and in $\mathrm{cm}$ was 0.08 (range $0-0.1367, \mathrm{n}=31, \mathrm{SD}$ $=0.0321, \mathrm{SE}=0.0006$ ), thus being practically imperceptible. This was also confirmed by a one-way ANOVA on the various replicates $\left(\mathrm{F}_{9,300}=0.000406, \mathrm{p}=1\right)$, and with an inter-classes correlation index showing a very high repeatability of the data (model: $\mathrm{r}=\mathrm{s} 2 \mathrm{a} /(\mathrm{s} 2+\mathrm{s} 2 \mathrm{a}), \mathrm{r}=931.7362 /$ $(0.380287+931.7362)=0.9995)$. It is therefore possible to conclude that for the application of model I only the mean values for each group should be used.

For generating the data function, only the measurements taken by the telemeter are used, with $\mathrm{X}$ being the distance and $\mathrm{Y}$ being the ratio elephant silhouette/number of pixels (in $\mathrm{cm}$ ). This index was repeated five times for each distance, and thus for each distance a table was built where under the column $\mathrm{Y}$ the five different index values are indicated, and under the column $\mathrm{X}$ the associated distance values. Then, a regression function was obtained from this table. In my case, the regression equation was $\mathrm{Y}=$ $0.007164 \mathrm{x}-0.007211 \pm 0.00876096$.

\section{Model II}

Potential errors in the measurements are linked to two independent sources: the rangefinder error and the human error in measuring the pixel size on the digital images.

The rangefinder error was estimated by comparing the distance from the cardboard silhouette in $\mathrm{cm}$ measured manually with the tape to the distance in $\mathrm{cm}$ obtained by the optical rangefinder (Fig. 4). On average, the rangefinder measurements were $55 \mathrm{~cm}$ greater than the manual tape measurements which would result in an error of $0.924 \mathrm{~cm}$ in shoulder height estimations.

The human error was estimated by taking ten replicate measurements in pixels on the same photo for 31distance classes. On average, the difference between the various measurements on the same photo image was of 0.16 pixels corresponding to an error of $\pm 0.0057 \mathrm{~cm}$ in shoulder height estimation. Thus, the human error in measuring 


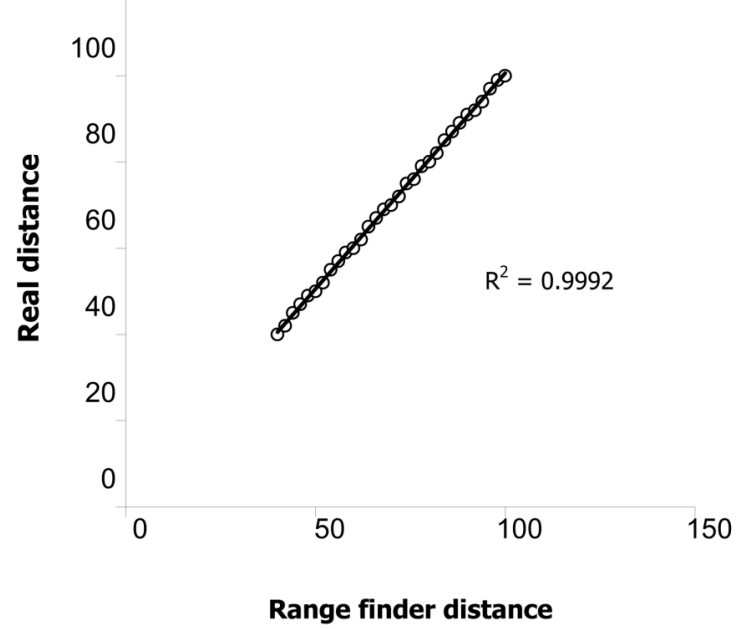

Fig 4. T-test comparing manually tape measured distances and rangefinder distances from the elephant cardboard silhouette. the elephant height from the digital images was irrelevant (one-way ANOVA: $\mathrm{F}_{9,300}=0.00, \mathrm{p}=0.98, \mathrm{ICC}=0.9995$ ).

\section{Comparing the two methods}

For brevity, in order to evaluate the performance of the two methods in characterizing the shoulder height of elephants, I present here only the comparisons for the smallest and the largest elephant silhouettes (Table 2). The average differences were very small (up to ca $3 \mathrm{~cm}$ out of 250 $\mathrm{cm}$ in the largest silhouette!). This demonstrates that the two methods not only provided very similar results, but also gave confident estimates of the actual elephant shoulder height. Therefore, they can be certainly used for field studies of these pachyderms. I used a relatively cheap camera-technology (priced ca $400 €$ ), and with a better equipment the accurateness of the estimates should have been even much better. The mean error measurements for all the silhouette sizes are given in Table 3.

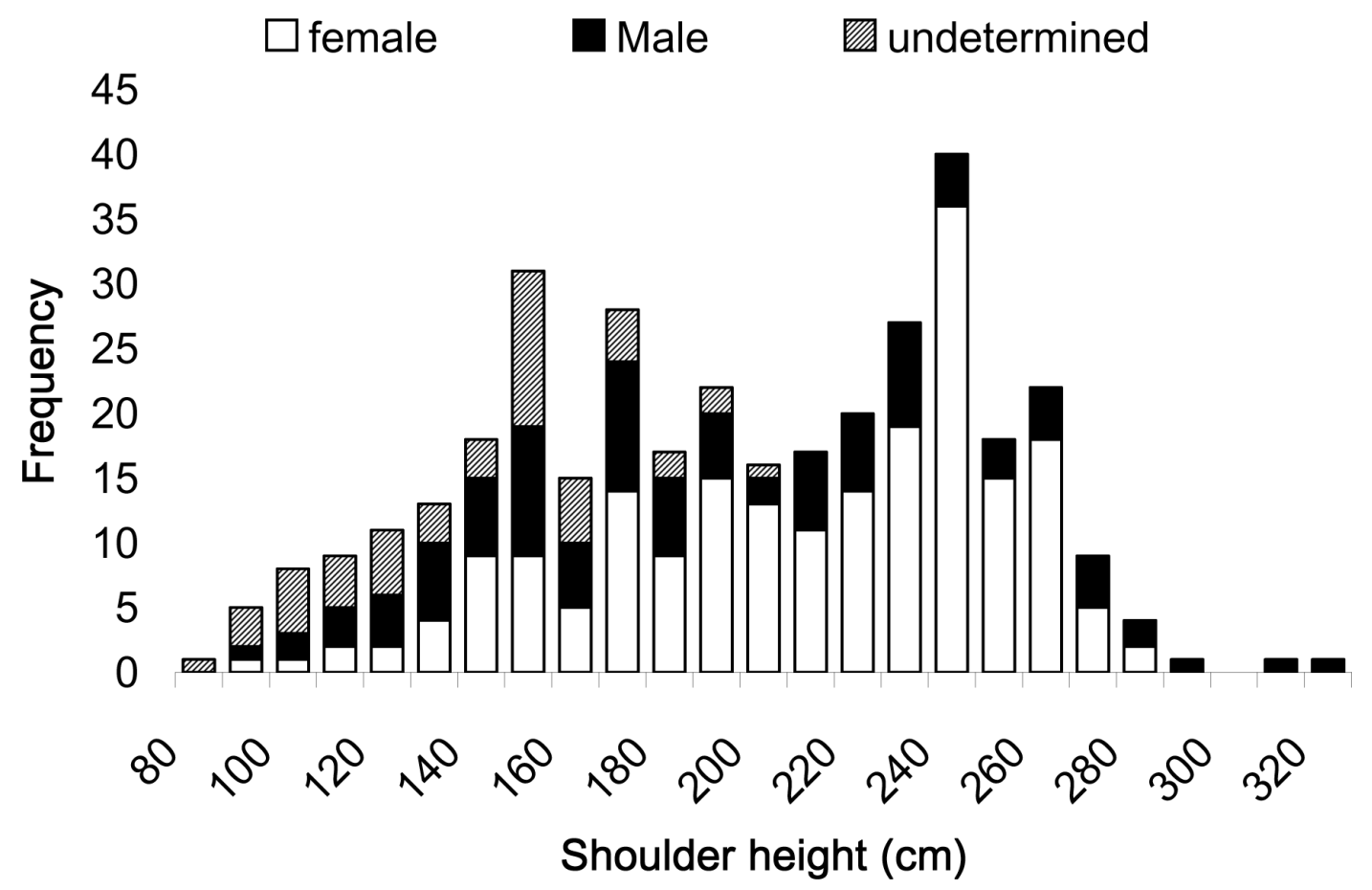

Fig 5. Frequency distribution of shoulder height for 352 identified elephants in Zakouma National Park, Chad (the mean of all measured individuals was $194.2 \pm 2.6 \mathrm{~cm}$, and the median was $195.2 \mathrm{~cm}$ ). Striped bars indicate newborn and young individuals; black bars indicate sub-adult and adult males; white bars indicate sub-adult and adult females. 
Table 2. Comparison of performance of the two methods used for the estimation of shoulder height of differently sized elephant silhouettes $(50 \mathrm{~cm}$ and $250 \mathrm{~cm}$ tall).

\begin{tabular}{|c|c|c|c|c|}
\hline $\begin{array}{l}\text { No. of } \\
\text { pixels }\end{array}$ & $\begin{array}{c}\text { Distance } \\
(\mathrm{m})\end{array}$ & $\mathrm{Y}$ & $\begin{array}{l}\text { Height by } \\
\text { function }\end{array}$ & $\begin{array}{l}\text { Height by } \\
\text { geometric } \\
\text { formula }\end{array}$ \\
\hline
\end{tabular}

\begin{tabular}{|c|c|c|c|c|}
\hline \multicolumn{5}{|c|}{$50 \mathrm{~cm}$ silhouette } \\
\hline 177.0 & 40 & 0.2 & 49.4 & 49.5 \\
\hline 169.1 & 42 & 0.2 & 49.6 & 49.7 \\
\hline 160.8 & 44 & 0.3 & 49.4 & 49.5 \\
\hline 154.9 & 46 & 0.3 & 49.9 & 49.8 \\
\hline 152.0 & 48 & 0.3 & 51.1 & 51.0 \\
\hline 141.6 & 50 & 0.3 & 49.6 & 49.5 \\
\hline 138.6 & 52 & 0.3 & 50.6 & 50.4 \\
\hline 131.9 & 54 & 0.3 & 50.0 & 49.8 \\
\hline 128.3 & 56 & 0.3 & 50.5 & 50.2 \\
\hline 124.2 & 58 & 0.4 & 50.6 & 50.4 \\
\hline 120.4 & 60 & 0.4 & 50.8 & 50.5 \\
\hline 117.7 & 62 & 0.4 & 51.4 & 51.0 \\
\hline 113.5 & 64 & 0.4 & 51.1 & 50.8 \\
\hline 108.7 & 66 & 0.4 & 50.5 & 50.2 \\
\hline 106.0 & 68 & 0.4 & 50.8 & 50.4 \\
\hline 105.1 & 70 & 0.4 & 51.9 & 51.4 \\
\hline 102.2 & 72 & 0.5 & 51.9 & 51.5 \\
\hline 99.2 & 74 & 0.5 & 51.8 & 51.3 \\
\hline 95.2 & 76 & 0.5 & 51.1 & 50.6 \\
\hline 93.0 & 78 & 0.5 & 51.2 & 50.7 \\
\hline 91.2 & 80 & 0.5 & 51.5 & 51.0 \\
\hline 90.5 & 82 & 0.5 & 52.4 & 51.9 \\
\hline 86.9 & 84 & 0.5 & 51.6 & 51.0 \\
\hline 81.2 & 86 & 0.6 & 49.4 & 48.8 \\
\hline 80.3 & 88 & 0.6 & 50.0 & 49.4 \\
\hline 79.8 & 90 & 0.6 & 50.8 & 50.2 \\
\hline 79.9 & 92 & 0.6 & 52.0 & 51.4 \\
\hline 76.8 & 94 & 0.6 & 51.1 & 50.5 \\
\hline 75.1 & 96 & 0.6 & 51.0 & 50.4 \\
\hline 73.2 & 98 & 0.6 & 50.8 & 50.2 \\
\hline 71.0 & 100 & 0.7 & 50.3 & 49.7 \\
\hline \multicolumn{5}{|c|}{$250 \mathrm{~cm}$ silhouette } \\
\hline 429.8 & 82 & 3.0 & 249.3 & 246.7 \\
\hline 420.2 & 84 & 2.9 & 249.8 & 247.0 \\
\hline 409.2 & 86 & 2.9 & 249.1 & 246.3 \\
\hline 399.5 & 88 & 2.8 & 248.9 & 246.0 \\
\hline 90 & 90 & 2.7 & 248.6 & 245.7 \\
\hline 384.7 & 92 & 2.7 & 250.7 & 247.7 \\
\hline 375.7 & 94 & 2.6 & 250.2 & 247.2 \\
\hline 359.8 & 96 & 2.6 & 244.8 & 241.7 \\
\hline 359.8 & 98 & 2.2 & 250.0 & 246.8 \\
\hline 352 & 100 & 2.5 & 249.6 & 246.4 \\
\hline
\end{tabular}

\section{Estimating the height of African elephants in Zakouma National Park, Chad}

During the study period, 352 individuals were photographed for calculation of shoulder heights: 317 females with their calf and 35 adult males. The shoulder height distribution is given in Fig. 5. The minimum shoulder height observed was $79.4 \mathrm{~cm}$, as other African populations
(Amboseli: Lee and Moss 1995; Murchison Falls: Laws et al. 1975). However, at Zakouma the adult females reached the height of $279.5 \mathrm{~cm}$, thus being among the tallest populations currently known (Fig. 6). For the adult males, the maximum shoulder height was $323.4 \mathrm{~cm}$, being significantly taller than females.

The height distribution by age classes is shown in Fig. 7 . Growth rates were highest throughout the first five yr of 
Table 3. Mean error measurements for shoulder height estimates of elephant silhouettes according to models (statistical and geometrical).

\begin{tabular}{lcccc}
\hline $\begin{array}{l}\text { Silhouettes } \\
(\mathrm{cm})\end{array}$ & $\begin{array}{c}\text { Y function } \\
(\mathrm{cm})\end{array}$ & $\begin{array}{c}\text { Error function } \\
(\mathrm{cm})\end{array}$ & $\begin{array}{c}\text { Y formula } \\
(\mathrm{cm})\end{array}$ & $\begin{array}{c}\text { Error formula } \\
(\mathrm{cm})\end{array}$ \\
\hline 50 & 50.82 & 0.82 & 50.47 & 0.47 \\
100 & 98.92 & -1.08 & 98.18 & -1.82 \\
150 & 148.77 & -1.23 & 147.43 & -2.57 \\
200 & 200.64 & 0.64 & 198.49 & -1.51 \\
250 & 249.16 & -0.84 & 246.19 & -3.81 \\
\hline
\end{tabular}

life. Between birth and five yr age, Zakouma elephants grew from a mean height of $79.4 \mathrm{~cm}$ to $168.5 \mathrm{~cm}$, with an overall increase of approximately $89 \mathrm{~cm}$ and a mean growth rate of $17.82 \mathrm{~cm} \mathrm{yr}^{-1}$. The body growth of females started to slow down by the age of 15 , when the male growth rate was still high: between ten to 15 years age, mean male growth per yr was approximately $7.15 \mathrm{~cm}$. Male growth started to slow down after the age of 25 (Fig. 8).

\section{Conclusions}

I compared the results of two easy to use models that can be useful to calculate the shoulder height of free-ranging elephants from a known distance. The Model I, based on a regression approach, is still to be validated in the field but appears to be valuable on the basis of the trial tests presented here. Model II, based on a geometric formula, was already applied to a free-ranging population of elephants in Zakouma National Park, Chad, and appeared to work well for this case study, as shown by Shrader et al. (2006a) on South African elephants. The estimated error for both models was low, indicating a strong accuracy. Nevertheless, especially in the case of Model II, even this small error should not be underestimated, as it allows establishing the height limit to be considered for measuring an accurate age of an individual. Since growth rate of elephant decreases with age, if our error limit is higher than the small size increases of aged elephants, then the accurateness of our method will fail.

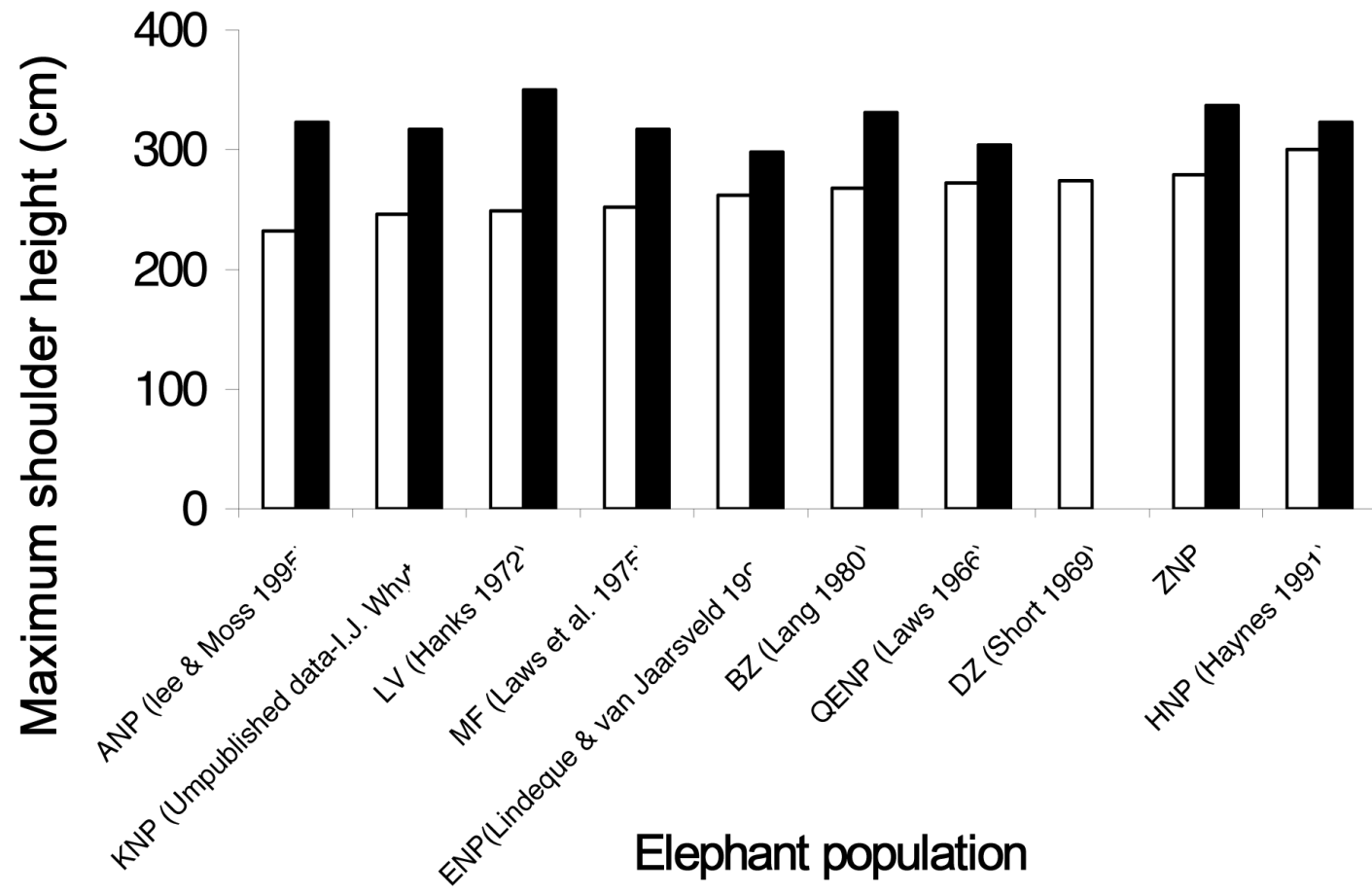

Fig. 6. Maximum shoulder height observed in different populations of African elephants. Numbers above the bars indicate the maximum height values. Black bars represent males, and white bars represent the females. ANP = Amboseli National Park; KNP = Kruger National Park; LV = Luangwa Valley; MF = Murchinson Falls; ENP = Etosha National Park; BZ = Basle Zoo; QENP = Qeen Elisabeth National Park; DZ = Diksie Zoo; ZNP = Zakouma National Park; HNP = Hwange National Park. 


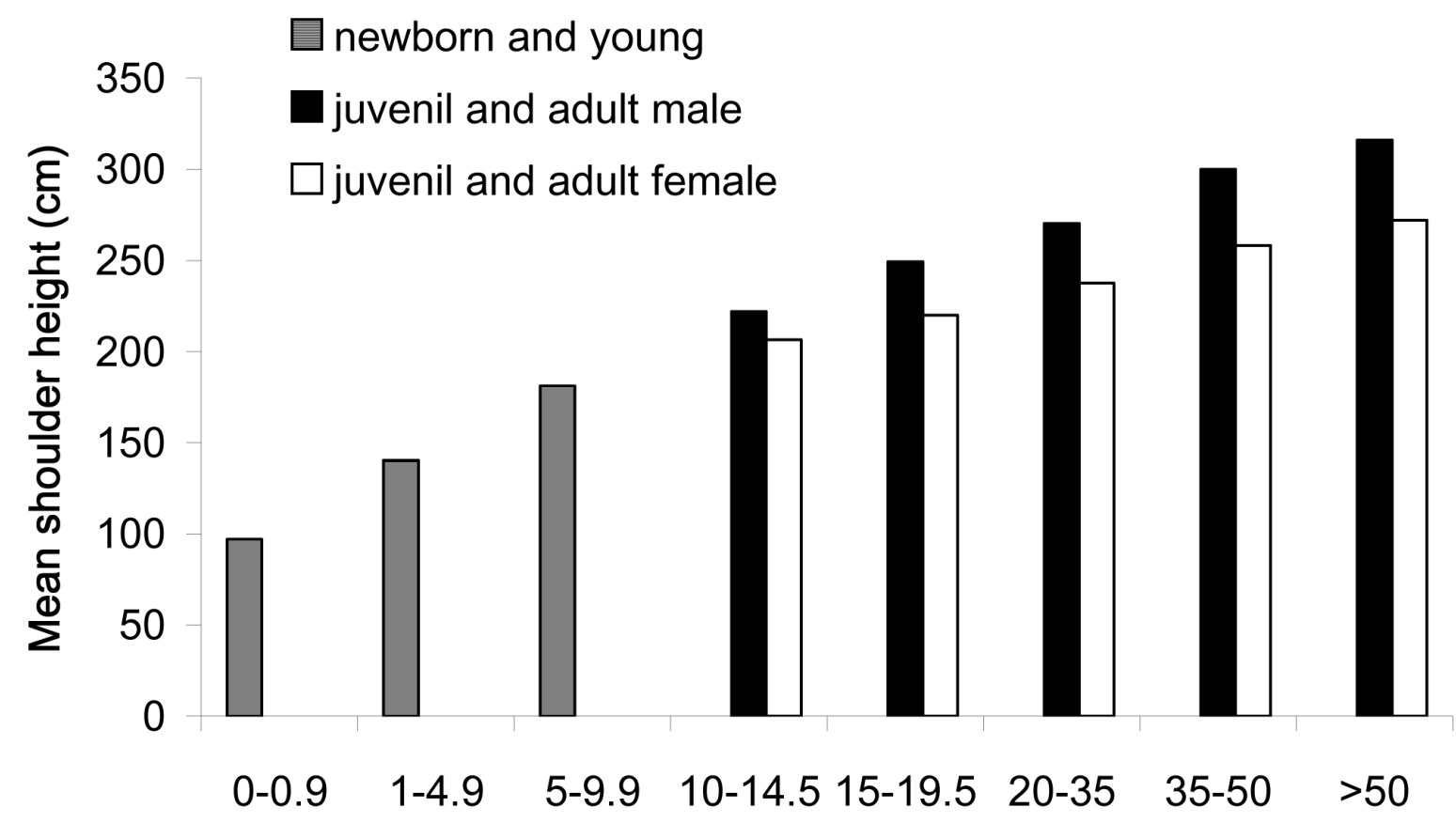

\section{Estimated age}

Fig. 7. Age distribution of African elephants as estimated by shoulder height for 352 identified individuals at Zakouma National Park, Chad.

With Model II it was possible to obtain accurate age estimations for the Zakouma elephants aged up to ten yr for females and $20 \mathrm{yr}$ for males. After this age, if we add the estimation errors to the real measure obtained from the two methods (estimation of size and estimation of age from the size), we come up with an estimation that is likely higher than the yearly growth rate, and this impedes to guarantee accurate age estimation. Therefore, after these ages it is advisable to subdivide the populations in age

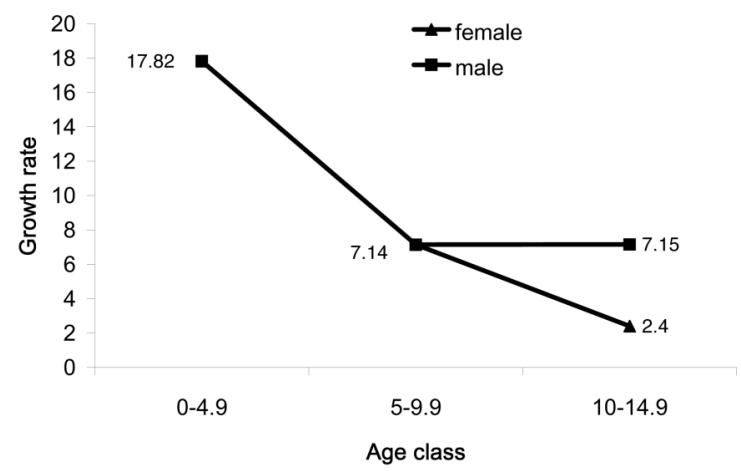

Fig. 8. Growth rates during the first $15 \mathrm{yr}$ of life for male and female elephants. classes and to rely on other morphological parameters, especially for individuals older than $20 \mathrm{yr}$ (Moss 1996).

A potentially relevant aspect of my study is that these methods can be easily applied to other savannah animals such as lions, rhinos, buffaloes, zebras, and giraffes in Africa and elsewhere. Obviously, it will be necessary to recalculate the measurement errors to avoid introducing biases in the analyses.

Acknowledgements - I thank Dr. A. Ortolani for insightful guidance over the research period, for helping me during the field and the laboratory work, and for reading over a early draft of this manuscript. I am also indebted to Prof. L. Boitani for support and encouragement, Dr. Louis Arranz (Director of the Zakouma National Park) and the authorities of the Chad government for authorizations to work in the Park, and C. Cacioppo, L. Massaro, and D. Petriccione for helping me during the silhouette trials and elephant identification. This study was partially supported by the Ministry for the Public Education of Italy.

\section{References}

Aubréville, A. 1950. Flore forestiére Soudano-Guinéenne. - Sociétés d'Editions Géographiques, Maritimes et Coloniales, Paris. 
Calenge, C., Maillard, D., Gaillard et al. 2002. Elephant damage to trees of wooded savanna in Zakouma National Park, Chad. - J. Trop. Ecol. 18:599-614.

Croze, H. 1972. A modified photogrammetric technique for assessing age-structure of elephant populations and its use in Kidepo National Park. - E. Afr. Wildl. J. 10: 91-115

Douglas-Hamilton, I. 1972. On the ecology of the African elephant. PhD thesis, University of Oxford.

Dejace, P. 1995. Rapport d'activité du parc national de Zakouma, 1993-1995. - Ministère de l'environnement et du tourisme, Tchad.

Dejace, P., Gauthier, L. and Bouché, P. 2000. Les populations des grands mammiferes et d' autruches du Parc National de Zakouma au Tchad: statuts et tendances évolutives. - Rev. Ecol. (Terre Vie) 55: 305-320.

Dolmia, M. and Cornélis, D. 2004. Dynamique spatiale des éléphants du Parc National de Zakouma: premiers résultats d'une étude en cours. - Revue Canopées 2004: 22-24.

Fleury, P., and Mathieu, J.P. 1956. Images optiques. - Paris, Eyrolles.

Hanks, J. 1972. Growth of the African elephants (Loxodonta africana). - E. Afr. Wildl. J. 10: 251-272

Haynes, G. 1991. Mammoths, Mastodons and Elephants. Cambridge Univ. Press.

Jachmann, H. 1988. Estimating age in African elephants: a revision of laws' molar evaluation technique. - Afr. J. Ecol. 26: 51-56.

Lang, E.M. 1980. Observations on growth sod molar change in the African elephant. - Afr. J. Ecol. 18: 217-234.

Laws, R.M. 1966. Age criteria for the African elephants. - E. Afr. Wildl. J. 4: 1-37

Laws, R.M. 1969. The Tsavo Research Project. - J. Reprod. Fert., Suppl. 6:495-531

Laws, R.M., Parker, I.S.C. and Johnstone, R.C.B. 1975. Elephants and their habitats: The ecology of elephants in North Bunyoro, Uganda. - Clarendon Press.
Lee, P.C. and Moss, C.J. 1995. Statural growth in the African elephant (Loxodonta africana). - J. Zool. (Lond.) 236: 2941.

Lindeque, M. and Van Jaarsveld A.S. 1993. Post natal growth of elephants Loxodonta africana in Ethosha National Park, Namibia. - J. Zool. (Lond.) 229: 319-030

Maillard, D., Calenge, C., Jacobs, T. et al. 2001. The Kilometric Index as a monitoring tool for populations of large terrestrial animals: a feasibility test in Zakouma National Park, Chad. Afr. J. Ecol. 39: 306-309.

Morgan, B.J. and Lee, P.C. 2001. Forest elephant (Loxodonta africana cyclotis) stature in the Réserve de Faune du Petit Loango, Gabon. - J. Zool. (Lond.) 259: 337-344.

Moss, C. J. 1996. Getting to know a population. - In: Kangwana, K. (Ed.), Studying elephants, African Wildlife Foundation, Nairobi, pp. 58-74.

Petriccione, D., Ardovini, A., Cinque, L. et al. 2006. Computeraided wild elephant identification. - In: Abstracts of the ISBE 2006, Tours, pp. 264.

Short, R.V. 1969. Notes on teeth and ovaries of an African elephant (Loxodonta africana) of known age. - J. Zool. (Lond). 158: 421-425.

Shrader A.M., Ferriera, S.M., and van Aarde, R.J. 2006a. Digital photogrammetry and laser rangefinder techniques to measure African elephants. - South Afr. J. Wildl. Res. 36: $1-7$.

Shrader, A.M., Ferreira, S.M., McElveen, M.E. et al. 2006b. Growth and age determination of African savanna elephants. - J. Zool. (Lond). 2006: 1-9.

Western, D., Moss, C. J. and Georgiadis, N. 1983. Age estimation and population age structure of elephants from footprint dimensions. - J. Wildl. Manage. 47: 1192-1197.

Wittemyer, G. 2001. The elephant population of Samburu and Buffalo Springs National Reserves, Kenya. - Afr. J. Ecol. 39: 357-365. 